\title{
Understanding Online Social Networking in Terms of Mental Health: A Boon or Bane?
}

\author{
Suyog V Jaiswal* and Deoraj Sinha \\ Department of Psychiatry, India \\ *Corresponding author: Suyog V Jaiswal, Assistant Professor, Department of Psychiatry, India
}

Submission: 眥 August 08, 2017; Published: 眥 September 25, 2017

\begin{abstract}
Online social networking is a fastest growing medium for connecting people with each other defying the physical barrier. The social networking can be a good support system to some of its users and help them get over their fear and anxieties of social interaction. Despite that it has a great potential for developing into an addicting behavior and this addicting behavior has similar implication as any chemical dependence syndrome. There is research which suggests that self esteem and personality of the users determine the way an individual uses the online social networking and it is suggested that use of social networking sites may be associated with depression. The link between depression and online social networking is complex and requires further study. Online social networking is a thing which has to cause as well as prevent mental health emergencies such as deliberate self harm and suicide. It is a tool which needs to be handled carefully and can be rewarding if done so.
\end{abstract}

Keywords: Social networking; SNS addiction; Social networking site; Psychiatry

\section{What is Online Social Network?}

Socialization is the pivotal step in evolution of humans which further laid out the way for a civilization. The socialization is human nature and we have a need to keep in touch with individuals in our society. Since the invention of internet and it became accessible to common people in mid 1990s, the user base of internet is growing at a steady rate. By 2016 around 3.5 billion people had access to internet and using it which more than $40 \%$ of world population [1]. With access to internet the social networking came into picture as a way of socialization over internet, sharing information and communication. Social network sites as web-based services that allow individuals to construct a public or semi-public profile within a bounded system, articulate a list of other users with whom they share a connection, and view and traverse their list of connections and those made by others within the system [2]. So for all practical purpose any online platform which registers users to share their personal information, establish connections and allows the access of information shared by other users to begin with. There are various social networking sites today available to users without any fees such as Facebook, Instagram, Twitter, MySpace, Google+, Tumblr, Pintrest and many others. Each social networking site has unique feature which differentiates itself from others but basic concept stays same as keeping in touch with other individuals and sharing information and views. We set out to review various psychological aspects of the relatively new phenomenon of socialization, online social networking. The aspects that we discussing here are social support, addictions of social networking sites and psychiatric morbidity.

\section{Social Network or Social Support Network?}

A social network service essentially consists of a representation of each user (often a profile), his/her social links, and a variety of additional services. Most social network services are web based and provide means for users to interact over the internet thereby clearing the hurdle of physical presence of audience and speaker to have an interaction. Compared to face-to-face interaction, computermediated or Internet-based communication lacks social cues [3]. Women are more likely to engage in online communication to maintain personal connections with family, friends, and co-workers, whereas men use online communication for pursuing sexual interests and romance [4]. In terms of generational differences, young adults spend more time using online communication and are more comfortable doing so as compared to older generations [5]. Online communication preferences evidence is mounting that online interaction may become the preferred mode of social contact for key groups of Internet users.

Communications on social network can offer expression of one's thoughts and feeling with the desired audience without restriction of physical distance. This expression can many times relieve a person of his or her painful emotions as well as offer emotional support. In teenagers using computer networks for social interaction relieves many aspects of group anxiety and makes them easy to approach members of opposite sex with some ease [6]. Infinite possibilities of the web help define alternative realities where anonymity is welcomed and potentially psychologically 
rewarding [7]. This anonymity often alleviates the social networking users of their anxieties and fear of being judged. The anonymity also allows one to observe the reactions to his or her expressions by the audience of one's immediate social circle as well as individuals out of the social environment of the user of social network. This has potential to bring objectivity about own thoughts and views as well validation of the thought process thereby enriching the thinking and evolving the personality of user. Rapid growth of these alternative realities is beneficial and ambiguity of social network profiles allows users especially adolescents to create an identity and find social acceptability without having to directly face scrutiny [8]. The avoidance of these scrutiny and way to overcome the social fears without overcoming it may be detrimental to evolution of personality. Overreliance on social networking technology at cost of real social connection may pave way for impoverishment of social skills and individuals unable to engage in meaningful conversations because such skills are being ignored for constant connection, resulting in short-term attention and a decreased ability to retain information [9]. Turkle describes it as "alone together": always connected via technology, but in fact isolated [10]. Despite that social networking can arguably be considered a way of being and relating than referring to what we do [11]. Social networking meets basic human needs such as needs of safety, association, estimation, and self-realization by offering the possibilities of social support and self-expression [12]. People who used the social networking site less frequently feel less satisfied with their lives, and it is speculated that social networking site could help individuals overcome low satisfaction and low selfesteem [2]. Offering the fulfillment of these basic needs can be a possible explanation to the current day exponential growth of the social networking sites and their unique selling point. Online social networking connects one to others from friends and family to strangers and celebrities and may help to establish and maintain friendships, express thoughts, feeling and anxiety [13,14]. Online social networking may augment the benefits of engaging in faceto-face interaction by extending the reach and accessibility of our social networks [14]. Online social networking is associated with lower levels of loneliness and greater feelings of belonging (social connectedness), social capital, and actual and perceived access to social support and is generally associated with higher levels of life satisfaction and self-esteem [15-17].

\section{Online Social Networking is a Habit or Addiction?}

As social networking has some advantages, similarly there are certain concerns about rapid growth and compulsive use of social networking sites among general population especially younger lot. Online social networking is in most cases a normal modern behavior which is fairly acceptable in the society. The addictions to various chemical substances is very well known, researched as well as diagnosed and treated by the mental health professionals but concepts of behavioural addiction is relatively new. Several behaviors tend to produce short-term reward that may engender persistent behavior despite knowledge of adverse consequences, i.e, diminished control over the behavior which is a core defining concept of psychoactive substance dependence or addiction [18]. The similarities between chemical addictions and behavioural addictions have been studied and established since [18-20]. Chemical and behavioral addictions have several phenomenological similarities such as salience, tolerance, mood modification, conflict, withdrawal, problems, and relapse [18,21]. Use of social networking in some cases is excessive and can be termed as pathological. This excessive use of social networking along with inability to cut down its use despite wishing to do so is pathological behavior which is suggested as behavioural addiction [22]. Andreassen and Pallesen [23] define social networking site addiction as "being overly concerned about social networking sites, to be driven by a strong motivation to log on to or use social networking sites, and to devote so much time and effort to SNSs that it impairs other social activities, studies/job, interpersonal relationships, and/or psychological health and well-being" They further suggest that individuals with social network addiction have features that they end up spending more time thinking about and on social networking site than intended; use social networking sites to counter feelings of guilt, anxiety, restlessness, depression and forget about personal problems. Andreassen and Pallesen [23] also state that prohibition of social networking sites causes stress, restlessness and irritability in these individuals and despite their decision to spend less time online they fail to do so resuming same pattern of use again. They also tend to ignore their partner, friend and family and use of social network negatively influences their health, sleep quality, relationship and well-being. It is suggested that the social networking addictions are specifically associated with certain personality traits such as extraversion [24]. Another study fails to support association of use of social networking site with extraversion but suggests individuals who are agreeable, neurotic individuals use social networking site more and individuals who are conscientious and emotionally stable use it to a lesser degree [25].

\section{Online Social Networking and Psychiatry, the Interface}

As social networking is helpful to some and addictive to some, it also has associations with a few psychiatric morbidities associated with it. Social networking sites and internet-related mental problems are frequently seen together with other psychiatric conditions or, in other words, these problems are complicated by comorbidity [26]. The researchers working with college student observed the relationship between dependency on a social networking site (Facebook) with poor quality of sleep as well as daytime dysfunction [27]. Moreover, in some cases, the Facebook dependence has been associated with relationship frustration as well as the emergence of jealousy [28]. Social network is a place where many individuals share the moments of their life such as photos and videos of their vacations, achievements and good times spend. These are once in public domain and seen by others among their connections gives rise to a natural comparison of others isolated moments of life with their own. This comparison may not be healthy at all times and in all individuals.

Researchers suggest that it is possible to get a clue of an individual's use of harmful substances by monitoring the social 
networking profile of him or her [29,30]. Using alcohol related reference in prominent and visible spaces such as Facebook profile picture or a photograph on social networking sites is associated with excessive alcohol use [31]. The link between depression and social networking is also being investigated and it is proposed that the depression is not only associated with use of social networking sites but severity of depression is also positively correlated with time spent on social networking sites [32]. However a recent review by Baker and Algorta [33] submit that the relationship between online social networking and depressive symptomatology may be complex and associated with multiple psychological, social, behavioural, and individual factors. They further imply that the impact of online social networking on wellbeing may be both positive and negative emphasizing need for further research in the area. Another area of concern is deliberate self harm and the way social networking sites affect it especially in children and young people who use social media to discuss and view deliberate selfharm. The use of social networking communities may affect a child/ young person's perceptions of deliberate self-harm and lead to maladaptive coping behaviors and the potential for triggering future acts of self-harm. The content of many of social media platforms are not in keeping with recommendations for responsible reporting of self-harm and suicide in the media, which are in place to minimize the potential negative impact on future actions, such as copycats, social contagion, and suicide clusters [34]. However, it not that the social networking sites are places where suicide and deliberate self harm is gets refuge but it can also be used to prevent such tragedies and find support systems for those dealing with mental health issues. Suicide notes or clues about potential suicide attempts on online social networks may allow for suicide prevention via the immediate intervention of other network users [35]. Despite all its flaws social networking site can and do form a good platform for establishing the mental health information and support forum for a large vulnerable population.

\section{Conclusion}

Online social networking is indeed a boon to human race. It helps people overcome their reservations and engage in socialization to begin with but does not have the potential to overcome the advantages of direct human communications. Online social networking has the addiction potential but can also be used in constructive ways. It's an influencer which may be used to influence a better world or worse which has to be determined by its users.

\section{References}

1. http://www.internetlivestats.com/internet-users/

2. Boyd DM, Ellison NB (2007) Social network sites: Definition, history, and scholarship. Journal of Computer-Mediated Communication 13(1): 210-230.

3. Joinson AN (2001) Self-disclosure in computer-mediated communication: The role of self-awareness and visual anonymity. European journal of social psychology 31(2): 177-192.

4. Weiser EB (2000) Gender differences in Internet use patterns and Internet application preferences: A two-sample comparison. CyberPsychology and Behavior 3(2): 167-178.
5. Howard PE, Rainie L, Jones S (2001) Days and nights on the Internet: The impact of a diffusing technology. American Behavioral Scientist 45(3): 383-404.

6. Subrahmanyam K, Greenfield P (2008) Online communication and adolescent relationships. Future child 18(1): 119-146.

7. Griffiths M (2000) Does Internet and computer 'addiction' exist? Some case study evidence. Cyber Psychology and Behavior 3(2): 211-218.

8. Czincz J, Hechanova R (2009) Internet addiction: Debating the diagnosis. Journal of Technology in Human Services 27(4): 257-272.

9. Turkle S (2015) Reclaiming Conversation: The Power of Talk in A Digital Age. Penguin, New York, USA.

10. Turkle S (2013) Alone Together. Why we expect more from technology and less from each other. Basic Books, Philadelphia, USA.

11. Kuss DJ, Griffiths MD (2017) Social networking sites and addiction: Ten lessons learned. Int J Environ Res public Health 14(3): 311.

12. Riva G, Wiederhold BK, Cipresso P (2016) Psychology of social media: From technology to identity. In The Psychology of Social Networking: Personal Experience in Online Communities. De Gruyter Open: Warsaw, Poland, pp. 1-11.

13. Wilson RE, Gosling SD, Graham LT (2012) A review of Facebook research in the social sciences. Perspect psychol Sci 7(3): 203-220.

14. Ellison NB, Steinfield C, Lampe C (2007) The benefits of facebook "friends:" Social capital and college students' use of online social network sites. Journal of Computer-Mediated Communication 12(4): 1143-1168.

15. Baek YM, Bae Y, Jang H (2013) Social and parasocial relationships on social network sites and their differential relationships with users' psychological well-being. Cyberpsychol Behav Soc Netw 16(7): 512517.

16. Guo Y, Li Y, Ito N (2014) Exploring the predicted effect of social networking site use on perceived social capital and psychological wellbeing of Chinese international students in Japan. Cyberpsychol Behav Soc Netw 17(1): 52-58.

17. Nabi RL, Prestin A, So J (2013) Facebook friends with (health) benefits? Exploring social network site use and perceptions of social support, stress, and well-being. Cyberpsychol Behav Soc Netw 16(10): 721-727.

18. Grant JE, Potenza MN, Weinstein A, Gorelick DA (2010) Introduction to behavioral addictions. Am J Drug Alcohol Abuse 36(5): 233-241.

19. Goudriaan AE, Oosterlaan J, De Beurs E, Van Den Brink W (2006) Neurocognitive functions in pathological gambling: a comparison with alcohol dependence, Tourette syndrome and normal controls. Addiction 101(4): 534-547.

20. Blanco C, Orensanz-Munoz L, Blanco-Jerez C, Saiz-Ruiz J (1996) Pathological gambling and platelet MAO activity: a psychobiological study. Am J Psychiatry 153(1): 119.

21. Griffiths M (2005) A 'components' model of addiction within a biopsychosocial framework. Journal of Substance Use 10(4): 191-197.

22. Andreassen CS, Torsheim T, Brunborg GS, Pallesen S (2012) Development of a Facebook addiction scale. Psychol Rep 110(2): 501-517.

23. Andreassen CS, Pallesen S (2014) Social network site addiction-an overview. Curr Pharm Des 20(25): 4053-4061.

24. Wilson K, Fornasier S, White KM (2010) Psychological predictors of young adults' use of social networking sites. Cyberpsychol Behav Soc Netw 13(2): 173-177.

25. Moore K, McElroy JC (2012) The influence of personality on Facebook usage, wall postings, and regret. Computers in Human Behavior 28(1): 267-274.

26. Block JJ (2008) Issues for Dsm-v. Am J Psychiatry 165(3): 306-307. 
27. Wolniczak I, Caceres-Del Aguila JA, Palma-Ardiles G, Arroyo KJ, SolísVisscher R, et al. (2013) Association between Facebook dependence and poor sleep quality: a study in a sample of undergraduate students in Peru. PloS One 8(3): e59087.

28. Elphinston RA, Noller P (2011) Time to face it! Facebook intrusion and the implications for romantic jealousy and relationship satisfaction. Cyberpsychol Behav Soc Netw 14(11): 631-635.

29. Moreno MA, Christakis DA, Egan KG, Brockman LN, Becker T, et al (2012) Associations between displayed alcohol references on Facebook and problem drinking among college students. Arch Pediatr Adolesc Med 166(2): 157-163.

30. Van Hoof JJ, Bekkers J, Van Vuuren M (2014) Son, you're smoking on Facebook! College students' disclosures on social networking sites as indicators of real-life risk behaviors. Computers in human behavior 34: 249-257.
31. Moreno MA, Cox ED, Young HN, Haaland W (2015) Underage college students' alcohol displays on Facebook and real-time alcohol behaviors. J Adolesc Health 56(6): 646-651.

32. Pantic I, Damjanovic A, Todorovic J, Topalovic D, Bojovic-Jovic D, et. al. (2012) Association between online social networking and depression in high school students: behavioral physiology viewpoint. Psychiatr Danub 24(1): 90-93.

33. Baker DA, Algorta GP (2016) The relationship between online social networking and depression: a systematic review of quantitative studies. Cyberpsychol Behav Soc Netw 19(11): 638-648.

34. Dyson MP, Hartling L, Shulhan J, Chisholm A, Milne A, et al. (2016) A systematic review of social media use to discuss and view deliberate self-harm acts. PLoS one 11(5): e0155813.

35. Ruder TD, Hatch GM, Ampanozi G, Thali MJ, Fischer N, et al. (2011) Suicide Announcement on Facebook. Crisis 32(5): 280-282. 